\title{
Direito do Trabalho e Direito Cooperativo A integridade é hercúlea, mas é possível criar à partir do impossível
}

Ghillerme Krueger

Resumo: A significação da cooperativa desde o amor inteligente de que fala a Encíclica Caritas in Veritate é partilhar um imaginário temporal para a cooperação. Este valor habita no imaginário e se articula com a juridicidade no direito. Possibilidades interpretativas para a Lei 12.690/2012 são concebidas a partir das ideias de identidade narrativa, de Paul Ricoeur e de desconstrução, de Jacques Derrida.

Palavras chave: Cooperativa, ato cooperativo, relações de trabalho, autogestão, direito.

Abstract: The meaning of cooperative based on the intelligent love mentioned in the Caritas in Veritate Encyclical letter is to divide an imaginary time gap for cooperation. This value is located in this imaginary space and is coordinated by Law. The different possible interpretations of Act 12.690/2012 are conceived based on Paul Ricoeur's ideas of narrative identity and Jacques Derrida's deconstruction ideas.

Key words: Cooperative, cooperative act, labour relations, self-management, Law. 
O que vem a ser cooperação na ordem constitucional? Como introdução a uma resposta possível, cito a encíclica Caritas in Veritate:

«Se o amor é inteligente, sabe encontrar também os modos para agir segundo uma previdente e justa competência como significativamente indicam muitas experiências no campo do crédito cooperativo $(\ldots.) \gg(\S 65)$

Desde já então fica evidente que reconheço a cooperação como um valor vital existente para o Direito antes mesmo de qualquer positivação e que é suportada por normas constitucionais. Eis pressupostos axiológicos com os quais é possível a abordagem do fenômeno cooperativo, seja ele manifesto como sociedade ou como ato, no Direito:

- Transcendência dos valores;

- Intuição emocional como via cognitiva;

- Valoração como um ato de preferência.

A cooperação então diz de uma vivência afetiva em sua originalidade no cerne do ato de preferência constitutiva do que vem a ser cooperativo; isto é, uma vivência como uma iniciação para a descoberta dos sentidos para essa expressão; isto é, um encontro que mergulha a cooperação na temporalidade (seu aparecimento), mas que, como absoluto, não se dissolve no tempo.

A cooperação é o valor com o qual pessoas se afetam para servirem umas às outras. Não se está aqui se referindo a um sentido hoje mais comum de prestação de serviços, como atividade de circulação de bens imateriais no mercado, mas exatamente a sua reversão, conquanto originalmente a servidão contrasta com a idéia de mercado, ou seja, com o sentido de se explorar a diferença entre o mínimo que o fornecedor e o trabalhador estão dispostos a receber por seus fatores de produção (insumos, serviços, equipamentos e mão de obra) e o máximo que o consumidor está disposto a pagar pelo produto material ou imaterial ofertado, para apropriação (alienação) marginal maximizada - o resultado líquido do exercício.

A cooperação, para ser cooperação, tem de ser gratuita. O sentido de servidão recíproca que há na cooperação realça a ausência de interesses patrimoniais opostos em suas operações. Compreender a cooperação como uma operação com um sentido próprio (servidão recíproca), faz emergir para a consciência um ente que pratica operações que diferem radicalmente das operações de mercado. Seu fundamento é a ausência de oposição de interesses de conteúdo econômico entre as pessoas que praticam o negócio. 
Mas, o imaginário propõe incessantemente intrigas singulares que desafiam e desarranjam o universal formal nomeado (sociedade cooperativa; ato cooperativo; propriedade cooperativa) como realidade (de) codificada. Há algo que escapa a todas as tentativas de análise dos negócios ou o patrimônio das cooperativas a partir de nomenclaturas ou de resultados, seja como empresa, seja como associação; seja o cooperado como dono, seja como usuário; seja o ato cooperativo representação, seja delegação; seja a propriedade cooperativa como direito real, seja ela como posse útil.

Em termos da ética pela qual se entrega a juridicidade, é de se desconfiar de toda razão (ontológica) própria, quando levada às conseqüências últimas, a totalização, sem qualquer (es)conjuração: «summum ius, summa iniura». O máximo do direito é a injúria máxima.

Trata-se do resgate da narrativa entre os fatos e o direito. Não exatamente como se fora estágios elementares exteriores entre si e constitutivos de um processo dialógico - descrição «neutra» do ser, e avaliação «racional» do dever-ser. Mas, como contramundo, no qual os valores pela ação narrada resistem por encantamento à pressão das pesquisas e às manobras do consenso.

Introduzo a Lei 12.690/2012 pelo mito de Antígona.

Creonte ascende ao trono de Tebas após uma luta fraticida entre Eteócles e Polinice, seus sobrinhos. Ambos já estão marcados por uma questão originária: a maldição lançada por Pélope sobre a dinastia Labdácida e consumada no parricídio de Édipo. Creonte (irmão de Jocasta) é movido pelo desejo de restabelecer a autoridade pública numa cidade afetada pela sucessão dos terríveis acontecimentos em torno de seu trono. Após a sangrenta guerra civil, ele condena Polinice post mortem por traição e decreta (kérugma) a mais afrontosa interdição: ele não deve ser enterrado. Contra essa afronta, se insurge Antígona, irmã dos falecidos. Ela evoca a tradição (agrapta nomima) em igualmente afrontosa desobediência. O desfecho? Antígona é enterrada viva. O filho de Creonte, noivo e apaixonado por Antígona, por desgosto se mata. A morte de Hêmon leva Eurídice, sua mãe e esposa de Creonte, ao suicídio. Creonte e Antigona fazem valer suas respectivas certezas ao preço do aniquilamento da fertilidade. Fenece a linhagem de Cadmo, fundador mítico de Tebas e avô de Lábdacos.

Os casos difíceis convocam um Hércules, disse Ronald Dworkin (2007. p. 287). E é bem conhecida a proposta dele para o Direito como romance em cadeia. Durante anos, sutilezas dialéticas não encontraram eco entre operadores do direito cooperativo e do direito trabalhista, tal como restou insolúvel o trágico antagonismo entre Antígona, demasiado orgulhosa, e Creonte, cruel ao levar suas razões e seus medos às últimas 
consequências. Antígona e Creonte nunca conseguirão se entender sobre a hierarquia dos direitos aplicáveis ao caso em que se confrontam.

Ambos, Creonte e Antígona, afirmam suas convicções, que se bastam a si mesmas. A questão fundamental na tragédia é a indeterminação da justiça. O direito se ressente da impetuosidade, na incontinência que abala a segurança erigida por seus institutos. Mas não pode prescindir da altivez, como uma de suas fontes imaginárias fundadoras: a historicidade no direito dá-se pela insistente tensão entre a consciência pessoal e a razão de Estado, sendo que ambos se legitimam por um senso de justiça, que nem sempre encontrará um modo de sobrepô-los sem desfechos trágicos.

Se, na democracia, o justo não pode se submeter à exatidão, a perplexidade suscitada pelo trágico indaga: como ordenar os atos livres para que haja justiça, na medida em que, paradoxalmente, o direito é contenção? O marginal precisa ser avaliado pela perspectiva da norma, tanto quanto o normal precisa ser reavaliado com a nova perspectiva aberta pela marginalização. Não é somente o normal que determina a norma, pois o marginal insinua o que precisa ser, de novo, normatizado.

Pois, os cooperativistas do ramo trabalho, por tanto tempo marginalizados, só abriram uma perspectiva nova para a Lei, quando admitiram que Lei é o que dá garantias fundamentais de um trabalho digno. Encontramos o futuro que Antígona e Creonte perderam.

O cooperativismo exerce um fascínio idílico sobre o operador do Direito do Trabalho. Esse fascínio advém da afinidade original e mítica do cooperativismo com o sindicalismo. Em que pese isso, há muitos pontos de interrogação entre o Direito Cooperativo e o Direito do Trabalho ${ }^{1}$. Revelam-se eles de modo particularmente inquietante na confluência de ambos os direitos sobre o mesmo objeto: a relação de

1 «De um lado, movimentos trabalhistas e movimentos cooperativos compartilham de um número de similariedades e sua interrelação é multi-facetada. Ambos estão centrados na condição humana. (....) De outro lado, movimentos trabalhistas e movimentos cooperativos representam diferentes abordagens da questão social. Os movimentos trabalhistas objetivam trazer à realidade leis trabalhistas para a proteção dos empregados, enquanto o movimento cooperativo reivindica o reconhecimento legal da autogestão. Esta diferença explicaria porque a importância sócio-político e econômico das interações entre ambos contrasta profundamente com o desinteresse pelo assunto. (....) Muito pouco existe sobre a conexão entre ambos. (....) Mesmo entre os países culturalmente próximos do cooperativismo, a questão -chave do que faz a relação de trabalho uma relação de emprego sobre a qual é aplicável a legislação trabalhista, faltam entendimentos comuns (....) A qualificação da relação de trabalho entre o associado e sua cooperativa em que pese regulações explícitas - é uma questão aberta.» (INTERNATIONAL LABOUR OFFICE. 1995. p. 3 -5). ISSN: 1134 - 993X, Núm. 47/2013, Bilbao, págs. 157-183 
trabalho. A cooperativa é uma idéia que consolida realizações anteriores à própria consolidação do paradigma trabalhista. Isso explica porque restaram suas premissas e propostas heteronômicas. Isso pode ser ilustrado a partir de uma leitura dos conceitos centrais do Direito Cooperativo e do Direito do Trabalho. Enquanto o primeiro tem em seu núcleo o ato cooperativo, o outro tem o vínculo de emprego.

A cooperativa é ainda hoje, antes de tudo, uma sociedade de iguais, afirmada pela singularidade do voto, o que remete as suas assembléias aos alvores da democracia, das ágoras. O ato cooperativo, como indica a expressão, é uma manifestação peculiar da vontade.

O cogito cartesiano ${ }^{2}$ ainda ocupa o centro desse Direito, pois ele, de certo modo, reflete racionalmente a vontade de cooperar. O ato cooperativo está assentado no contratualismo ${ }^{3}$, uma das fontes filosóficas do Direito Moderno. Se tivéssemos de concentrar em uma única expressão a argumentação das cooperativas de trabalho nos tribunais nas últimas décadas, chegaríamos talvez no pacta sunt servanda 4 .

2 «(...) enquanto eu queria assim pensar que era tudo falso, cumpria necessariamente que eu, que pensava, fosse alguma coisa. E, notando que essa verdade: eu penso, logo existo, era tão firme e tão certa que todas as mais extravagantes suposições dos céticos não seriam capazes de abalar, julguei que podia aceitá-la sem escrúpulo, como o primeiro principio da Filosofia que procurava». DESCARTES, René. Discurso do Método in: Os Pensadores. vol. XV. São Paulo: Abril Cultural, 1973, p. 54

3 O contratualismo mantém vitalidade na filosofia política contemporânea e repercussões no Direito sobretudo pelas contribuições de John Rawls. Rawls propõe reequacionar uma teoria de Justiça considerando a pluralidade das sociedades contemporâneas. Ele propõe um conceito de justo a partir do uso da razão e da vontade das pessoas. A estrutura básica da sociedade é, para Rawls, erigido a partir de uma posição original não histórica, um acordo hipotético entre os membros de uma sociedade, enquanto cidadãos e não enquanto indivíduos que ocupam uma posição ou papel particular no seio da sociedade.

A pretensão da teoria elaborada por Rawls é a de que princípios da justiça podem ser derivados do interesse próprio racional dos indivíduos, desde que eles sejam colocados, na «posição original», em determinadas condições ideais - no caso, sob o "véu de ignorância» Esse "véu» é uma hipotética impossibilidade do indivíduo antecipar o saldo concreto de vantagens para si obtidas dessa estrutura, de modo que, mesmo pensando de forma egoísta, optará pela equanimidade como modo mais justo. O "véu» é uma apropriação analítica. Ele existe como ponto de fuga para uma perspectiva para a escolha consensual de uma concepção particular de justiça. Esse "véu», de certo modo aproxima, Rawls da fenomenologia de Heidegger, pois o ser está entregue a si mesmo. Assim como Heidegger, Rawls parte do mistério (ontologia do ser) para a articulação da liberdade (moral), e então alcançar a existência histórica (política).

4 Hans Kelsen se destacou na Ciência Jurídica ao formular a Teoria Pura do Direito, na qual estabeleceu a conhecida hierarquização de normas. Para Kelsen, uma norma se legitima por outra norma superior numa ascendência piramidal até alcançar uma norma primeira fundamental e universal, denominada de Grundnorm, que por algum tempo irá identificar como a norma consuetudinária pacta sunt servanda. 
O vínculo de emprego é um contrato-realidade 5 , em que dele se extrai um elemento constitutivo do conceito: a assimetria das partes manifesta na hipossuficiência de uma delas. No Direito do TrabaIho, portanto, a potência volitiva individual cede espaço no seu âmago, que revela uma noção de justiça focada nas relações sociais mantidas por sujeitos massificados com interesses estruturalmente opostos e potencialmente em conflito, as categorias profissionais e econômicas. O vínculo de emprego decorre de um contrato com função social, por excelência e, como tal, a liberdade das partes está bem limitada por intervenção do Estado de Direito.

Os conceitos de contrato-realidade e hipossuficiência no direito do trabalho são, de certo modo, ecos do hegelianismo ${ }^{6}$. Hegel formulou uma estrutura dialética para devir: a coruja de Minerva voa à tardinha. O humanismo tendia, como um motivo central do pensamento liberal europeu, a colocar o «sujeito» no centro da análise e da teoria, vendoo como a origem e a fonte do pensamento e da ação. Esse humanismo se traduziu em Hegel na estruturação racional da história, que, quanto mais acentuado, mais via os sujeitos como portadores de estruturas, e menos como potências volitivas. Um certo hegelianismo que já esteve em voga privilegiava os objetos, conceitos de coletividade em que en-

5 «Não há uma separação, uma autonomia absoluta entre contrato e relação de emprego, como se fossem duas realidades distintas no plano jurídico, nem a doutrina alemã relacionista pode servir de base para tal conclusão. Nela a empresa é uma continuidade de trabalho que enfeixa uma só relação, unitariamente considerada, entre o empregador e os empregados, um todo a serviço do nacional-socialismo.

Para alguns, como Mario de la Cueva, o contrato é o acordo de vontades e a relação de emprego é o conjunto de direitos e obrigações que se desenvolvem na dinâmica do vínculo, daí usar a expressão 'contrato - realidade'. Nesse caso, o contrato é a fonte da qual a relação de emprego é o efeito que se consubstancia com a prestação material dos serviços no complexo de direitos e deveres dele emergente (...). (NASCIMENTO, Amauri Mascaro. Curso de Direito do Trabalho. SP: Saraiva, 2005, p. 553)

"Relação de emprego é um contrato, cujo conteúdo mínimo é a lei, possuindo como sujeitos, de um lado, o empregado, que presta serviços, e, de outro lado, o empregador, em função de quem os serviços são prestados de forma subordinada, habitual e mediante salário». (NETO, Francisco Ferreira Jorge; CAVALCANTI, Jouberto de Quadros Pessoa. Manual de Direito do Trabalho. V. 1. RJ: Lúmen Juris, 2004, p. 205)

6 O estruturalismo que se consolidou como uma forma de pensar no séc. XX, no entanto, partiu de um método inicialmente proposto por Saussure, ao distinguir a fala e a língua. Nessa distinção, percebeu na língua um sistema de relações entre significantes e significados e, ao analisar os padrões dessas relações, lançou as bases da semiótica. O estruturalismo, no final das contas, acabou por recusar o Aufhebung no sentido hegeliano, em que o que é suspenso (aufgehoben) agora se resolve futuramente, em um processo reconciliador. No pensar estruturalista, particularmente desenvolvido por Levi-Strauss, as estruturas são sempre sincrônicas, e é recusada a existência de estruturas diacrônicas. ISSN: 1134 - 993X, Núm. 47/2013, Bilbao, págs. 157-183 
cerravam o sujeito: classes sociais e econômicas, mais especificamente suas relações, mais ainda, os padrões nas relações. Esse pensar emprestava ao sujeito um elemento governado por estruturas e sistemas ao mesmo tempo em que paradoxalmente era capaz de um sobrevoo de inspeção da história.

É compreensível que operadores do Direito do Trabalho venham a ter uma relação ambígua em relação à cooperativa. De um lado, tecem loas em prosa ao cooperativismo. Mas, na prática, freqüentemente optam pelo afastamento do ato cooperativo do mundo do trabalho, ou, pelo menos, relegam a uma manifestação tão periférica, quanto a autonomia volitiva pessoal está relegada na realidade construída nesse universo trabalhista.

Retomando a composição matricial do direito cooperativo e o direito trabalhista, há um relativo consenso na doutrina jurídica internacional do que deve se diferenciar entre a relação jurídica-trabalhista e a relação jurídica-cooperativista: a primeira é claramente trabalhista e a outra, societária. Em conseqüência, uma é objeto do Direito Trabalhista e a outra das regras de contrato de sociedade. Trata-se de uma distinção clara. No caso das cooperativas da maioria das cooperativas, não há ocasião de conflito entre os valores trabalhistas e as regras cooperativistas.

Entretanto, pode surgir o conflito nas cooperativas de trabalho, já que se está cooperando nada menos que no próprio trabalho. Esse é o núcleo do problema. Evidentemente, se no mundo do trabalho protege-se às crianças, se se aceitam critérios irredutíveis de seguridade, de dignidade humana etc., no âmbito cooperativo não se desconsidera estas normas fundamentais.

Porém, se as normas fundamentais comuns ao Direito trabalhista e Direito cooperativo devem ser observadas, há uma evidente dificuldade de se encaixar o trabalho cooperativado no arcabouço jurídico construído pelo Direito Trabalhista.

Pode-se demonstrar o afirmado a partir da inaplicabilidade direta do sistema analítico de DUNLOP sobre as relações trabalhistas (OIT:1995). O modelo apresenta três protagonistas: os empresários, os trabalhadores e o Estado como legislador ou fiscalizador. Os três protagonistas se inter-relacionam e produzem as regras que regem as relações de trabalho, sob a influência das condições ambientais: as condições de mercado, o desenvolvimento tecnológico e a distribuição de poder na sociedade. Ainda os protagonistas agem a partir de certos sistemas de valores que formam suas ideologias.

Entretanto, as cooperativas unificam em um único agente social (protagonista) papéis que as sociedades empresariais em geral sepa- 
ram: São proprietários da cooperativa, ao mesmo tempo em que são seus provedores ou clientes. Trata-se do princípio da identidade, ou da dupla qualidade que caracteriza a cooperado. Essa dupla qualidade advém do regime autogestionário e auxiliar que caracteriza a cooperativa. A dupla qualidade dos membros da cooperativa explica-se porque este tipo de sociedades inverte os meios e fins que caracterizam as sociedades empresariais não cooperativas: enquanto nestas, a atividade societária é um meio de alcance dos fins empresariais (lucro), nas cooperativas, as atividades empresariais são o meio de alcance do objetivo societário (acréscimo de renda direto ou indireto). Desse modo, no caso das cooperativas, o seu associado tem um peso tal sobre as suas atividades que deve ser encarado como um quarto personagem no sistema de DUNLOP, conforme propõe HERNANDEZ (OIT: 1995) (ANEXO).

A identificação do ato cooperativo de trabalho representa um grande salto qualitativo, na busca da síntese no discurso cooperativista. Invenção latino-americana, a teoria do ato cooperativo, contribui para a construção de uma realidade autoreferenciada para as cooperativas, afirmando-as como entidades de natureza própria e autônoma em relação às referências que o discurso cooperativista ainda toma emprestado de outras realidades?.

A teoria do ato cooperativo encontrou repercussão e projeção nos Congressos Continentais de Direito Cooperativo realizados pela Organização das Cooperativas da América. Se o I CCDC (Mérida, 1969) focou o delineamento conceitual do ato cooperativo ${ }^{8}$, no II CCDC, em

7 «No direito português, o ato cooperativo não existe como categoria jurídica autônoma. Esta situação não distingue Portugal dos outros países europeus. Mas esta é uma ausência que confunde. De fato, ela facilita alguma incerteza no regime jurídico das cooperativas e é incongruente com a forte presença da realidade cooperativa na ordem jurídica portuguesa»

«A noção de ato cooperativo integra um território conceitual gerado pela convergência de dois processos: o da emergência de um setor autônomo no seio dos atos jurídicos; e o da valorização jurídica da especificidade de certos aspectos do funcionamento das cooperativas.» NAMORADO, Ruy. O Acto Cooperativo: Uma ausência que confunde. In: PENSAMENTO COOPERATIVO. Lisboa : Organização das Cooperativas Brasileiras / Instituto António Sérgio do Sector Cooperativo. Nº 3 [jun. 2002] p. 165.

8 A Carta de Mérida (I CCDC, 1969), em seu item 1.4. acatou a aproximação da noção conceitual de ato cooperativo proposto pelo emérito jurista argentino DANTE CRACOGNA:

«1.4 Que entre os elementos essenciais dos atos especificamente cooperativos, que permitem sua diferenciação frente a toda classe de atos cooperativos, se encontram:

SUJEITO: O cooperador, nesta condição e a cooperativa, enquanto está constituída e funciona de acordo com os princípios cooperativos universalmente aceitos;

OBJETO: De acordo com os fins da cooperativa; e

SERVIÇO: sem ânimo de lucro.» 
1976, a aplicação do conceito no mundo do trabalho suscitou debates. Em seu item 1.3.3, a Carta Jurídica de San Juan declarou o princípio de que a relação entre o trabalhador sócio de uma cooperativa de produção ou de trabalho e esta, é uma relação societária que estabelece vínculo jurídico cooperativo determinado pelo estatuto. Isso sem prejuízo da inscrição desse trabalhador sócio nos sistemas de seguridade pertinentes, em vigência nos respectivos países. ${ }^{9}$

Embora o II CCDC claramente reafirmasse a preponderância do contratualismo sobre o historicismo hegeliano no Direito Cooperativo, sua resolução já esboçava a particularidade atenuante de seus efeitos na aplicação do conceito de ato cooperativo no mundo do trabalho, ao admitir que o sócio, na condição de trabalhador, se integrava necessariamente aos sistemas pátrios de seguridade social.

O III CCDC, ocorrido em Rosário, 1986, deliberou pela elaboração da Lei Marco para as Cooperativas da América Latina, e determinou suas diretrizes:

«Em relação às cooperativas de trabalhadores há consenso de que se trata de um ato ou contrato de sociedade para trabalho em comum, onde todos os sócios estão num mesmo nível, não existindo dependência laboral.

«Para a solução prática preventiva de possíveis injustiças, há várias alternativas possíveis, desde que a que assinala a aplicação — por extensão- a legislação trabalhista comum, até a que parte da premissa da autoregulação dos direitos e obrigações por cada grupo cooperativo, como princípio autogestionário, passando pela que estabelece na lei própria um estatuto próprio que outorgue a esses trabalhadores alguns direitos fundamentais mínimos que somente poderiam ser suprimidos mediante uma votação qualificada» ${ }^{10}$.

Percebe-se nitidamente que os cooperativistas reconheceram no III CCDC que o mundo do trabalho impõe ao ato cooperativo uma ponderação para seus pressupostos contratualistas, embora ainda não houvesse consenso de como tal ponderação se daria.

Na consecução da proposta formulada no III CCDC, a Organização das Cooperativas das Américas realizou dois Seminários Internacionais sobre Atualização da Legislação Cooperativa, em 1987 e 1988, ambos em Santa Cruz de la Sierra. O texto final do projeto foi aprovado pela

9 MONTOLÍO, José Maria. Legislación Cooperativa en América Latina: Situación, Derecho comparado y Proceso de armonización. Madrid: Ed. Ministerio de Trabajo e Seguridad Social, 1990, p. 494.

10 MONTOLÍO. Ob. Cit., p. 527. 
VIII Assembléia da OCA. O art. $7^{\circ}$ da Lei Marco, em sua redação original, assim definia o ato cooperativo:

«São atos cooperativos os realizados entre as cooperativas e seus sócios ou pelas cooperativas entre si em comprimento de seu objetivo social e ficam submetidas ao direito cooperativo. Os vínculos das cooperativas com seus trabalhadores dependentes se regem pela legislação trabalhista» ${ }^{11}$.

A aplicação do conceito no mundo do trabalho foi a única merecedora de menção à altura da definição conceitual geral do ato cooperativo. Isso revelava a preocupação dos cooperativistas com as questões teóricas e práticas que essa aplicação suscitava. Por outro lado, a redação adotada reflete as incertezas encontradas no então estado das artes, já expressas no III CCDC. O ato cooperativo no mundo do trabaIho é afirmado por definição residual e cominação com o art. $8 .^{\circ}$, que declara a possibilidade de existência de cooperativas de trabalhadores. Assim, a Lei Marco fazia a distinção entre o trabalhador dependente e o trabalhador sócio, não dependente. Ao primeiro, afirma a aplicabilidade da legislação trabalhista, mas se omitia sobre o regime jurídico aplicável ao segundo, senão pela genérica remissão ao direito cooperativo, cuja solução ao problema do trabalho digno restava em aberto.

O IV e último CCDC (Brasília, 1992), manteve o foco no estudo dos efeitos do ato cooperativo nas relações de trabalho. Além de terem sido abordados na tese central ${ }^{12}$ dos trabalhos temáticos sobre o ato cooperativo, foi objeto de duas das sete teses de apoio apresentadas sobre o tema no Congresso ${ }^{13}$. As conclusões do IV CCDC sobre o ato cooperativo trouxeram sensível avanço no estado das artes, orientada para uma posição intermediária entre a mera aplicação da legislação trabalhista e a ausência de normas de direito público (autoregulação assemblear pura):

«Em relação às cooperativas de trabalho, os atos dos sócios com elas são atos cooperativos e se regem pela legislação específica das cooperativas.

11 MONTOLÍO. Ob. Cit., p. 533.

12 Efeitos do ato cooperativo na distribuição, no provisionamento, no trabalho associativo e no sistema financeiro), de autoria de Carlos Torres y Torres Lara (Peru).

13 O ato cooperativo na América Latina em relação ao trabalho associado, de Enrique Matzkin (Argentina) e O Ato cooperativo das cooperativas de trabalho: necessidade de um regime específico, de Beatriz do Couso e Cláudia Dovenna (Argentina). 
«A regra deve ser que todos os trabalhadores sejam sócios e, excepcionalmente, que não sejam sócios.

«Destaca-se a necessidade de que o ato cooperativo de trabalho não seja utilizado com fins de burla à legislação de ordem pública laboral, desnaturando as cooperativas.

«Deve ratificar-se a vigência de um vínculo societário, sempre e quando não se prove a fraude trabalhista, em cujo caso seria aplicável o regime dos trabalhadores dependentes.

"A cooperativa de trabalho deve atuar em todos os seus atos como cooperativa durante o transcurso da relação societária, e se assim não o fizer, também não poderá invocar a natureza cooperativa em juízo, pois se poria em contraposição com o seus próprios atos.

«É necessário — de lege ferenda- ditar normas que garantam os direitos sociais dos trabalhadores sócios em matéria de custos laborais e outros, descartando o que desnaturaria as cooperativas de trabalho como a indenização por demissão ou similares, que são próprios dos trabalhadores dependentes.

«É necessário que as cooperativas possam optar pelo sistema de custos que estimem mais conveniente e, em relação com as propostas concretas contidas nos trabalhos, se expressam distintas opiniões sem conclusão unânime» ${ }^{14}$.

Em 1998, com a instituição da CICOPA AMERICAS-Seção Regional da Organização Internacional de Cooperativas de Produção Industrial, Artesanal e de Serviço, entidade subsidiária à Aliança Cooperativa Internacional, foi emitida a Carta de Montevidéu, que avança ainda mais no reconhecimento da necessidade de normas de direito público determinantes do regime jurídico aplicável ao ato cooperativo de trabalho:

«As Cooperativas de Trabalho exigem dos governos normas claras, precisas e coerentes que facilitem o seu desenvolvimento, garantam o acesso de seus sócios à seguridade social e reconheçam as diferenças com o trabalho dependente, ao mesmo tempo que impeça a sua utilização violando direitos trabalhistas.»

Por fim, a Assembléia Geral da Aliança Cooperativa Internacional, reunida em Cartagena, nos dias 22-23 de Setembro de 2005 aprovou a Declaração Mundial sobre as Cooperativas de Trabalho. Este documento deu um decisivo salto doutrinário, ao afirmar que o ato cooperativo pode gerar uma relação de trabalho distinta tanto do traba-

14 ORgANIZACIÓN DE LAS COOPERATIVAS DE AMÉRICA.. Derecho Cooperativo Tendencias actuales en Latinoamerica y la Comunidad Economica Europea. Bogotá : Antropos, 1993. pp. 136-137. 
Iho subordinado como do trabalho autônomo individual ou por conta própria:

«Na atualidade os seres humanos realizam seus atos de trabalho sob três modalidades básicas: a)em forma independente, ficando neste caso determinado pela suas próprias capacidades e auto-regulação; b) em forma dependente assalariada, sob a continuada subordinação a um empregador o qual se limita a reconhecer-lhe uma remuneração produto de negociações individuais ou coletivas; c) sob uma terceira forma, a do trabalho associado, onde o trabalho e a gestão se realizam conjuntamente, sem as limitações próprias do trabalho individual nem exclusivamente sob as regras do trabalho assalariado dependente.

«Dentro das modalidades do trabalho associado, o organizado por intermédio das cooperativas é o que mais desenvolvimento e importância alcançaram no atual momento no mundo e está estruturado com fundamento nos princípios, valores e métodos de operação que possuem as cooperativas em nível universal e que estão consagrados na Declaração sobre a Identidade Cooperativa (Manchester, 1995), definidos no marco da Aliança Cooperativa Internacional, e incluídos na Recomendação 193/2002 da OIT sobre a Promoção das Cooperativas.

\section{(...)}

«Embora a ACl também integre as cooperativas de artesãos individuais e outras formas empresariais cooperativas que atendem aos conceitos centrais de trabalho e produção, a presente declaração está dirigida às cooperativas de trabalho associado (....)

\section{(...)}

«Em particular, é necessário que os Estados:

«Reconheçam em suas legislações que o cooperativismo de trabalho associado está condicionado por relações trabalhistas e industriais distintas do trabalho dependente assalariado e do auto emprego ou trabaIho individual independente, e aceitem que as cooperativas de trabalho associado apliquem normas e regulamentos correspondentes.»

Nesse passo, aproxima o ato cooperativo de trabalho do conceito da parassubordinação. A parassubordinação, que pode ser pensada como constituída pelo ato cooperativo de trabalho em processos de terceirização, é definida por AMAURI MASCARO DO NASCIMENTO em sua já mencionada obra (pp. 319-320):

«O trabalho parassubordinado é uma categoria intermediária entre o autônomo e o subordinado, abrangendo tipos de trabalho que não se enquadram exatamente em uma das duas modalidades tradicionais, entre os quais se situa, como a representação comercial, o trabalho dos profissionais liberais e outras atividade atípicas, nas quais o trabalho é prestado com pessoalidade, continuidade e coordenação.» 
Ao mesmo tempo em que a $\mathrm{ACl}$ afirma categoricamente:

«No seu funcionamento interno, as cooperativas de trabalho associado deverão ter em conta as seguintes regras:

(...)

«Combater sua utilização como instrumento para flexibilizar ou fazer mais precárias as condições de trabalho dos trabalhadores assalariados e não atuar como intermediários convencionais para postos de trabalho.

(..)

«Em particular, é necessário que os Estados:

(...)

«Apliquem às cooperativas de trabalho associado o conceito de trabalho decente e digno da OIT e disposições claras, precisas e coerentes que regulem a proteção social ou referente a saúde, pensões, dispensa, saúde ocupacional, e segurança industrial, tendo em conta o caráter específico das suas relações trabalhistas.»

Como se depreende, a doutrina cooperativista internacional finalmente logrou informar as diretrizes necessárias para alinhar uma posição cooperativista modal em nível nacional. Nesse mister, a Organização das Cooperativas Brasileiras, divulgou os Critérios para Identificação da Coo-

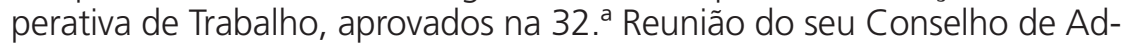
ministração, realizada em 06/12/2004, em Cuiabá-MT.

Eram premissas fundamentais desse documento:

- Inadequada a mera sujeição do trabalho cooperativo ao arcabouço jurídico construído pelo Direito Trabalhista (hipossuficiência do trabalhador), mas isso não impede a prática de atos cooperativos de trabalho na prestação de qualquer serviço.

- Entretanto, ainda que decorrente de ato cooperativo, a relação de trabalho não eventual e coordenado pela própria cooperativa $^{15}$ exige especial orientação para defesa da sua dignidade e decência ${ }^{16}$;

15 «Ora, ainda que organizados os associados de cooperativas de trabalho em equipes hierarquizadas para prestação de serviços, preservada a impessoalidade em relação ao tomador dos serviços, não resta desnaturada a autonomia dos mesmos para efeitos de legislação trabalhista, por inexistir no caso a hipossuficiência. A subordinação jurídica de que trata o art. $3 .^{\circ}$ da CLT não se configura, ante os princípios da soberania assemblear e da singularidade de voto que presidem a sociedade cooperativa (regime de autogestão).»

16 «Embora adotem premissas e proponham soluções conceitualmente diferentes, o Cooperativismo e o Direito do Trabalho comungam da compreensão do trabalhador como ente socioeconômico que demanda dignidade e defesa.» 
— Essa orientação pressupõe existência de direitos individuais dos trabalhadores sócios que não estão disponíveis para uma decisão assemblear, o que significa admitir que existem custos sociais mínimos irredutíveis e inegociáveis no ato cooperativo de trabalho ${ }^{17}$;

- Esses direitos individuais são informados no art. $7^{\circ}$ da Constituição Federal, embora seus incisos também incluam direitos inerentes à relação de trabalho tipicamente subordinada ${ }^{18}$.

Estes foram os passos de convergência dados pelos cooperativistas. Mas como operadores do direito trabalhista encararam o desafio das cooperativas de trabalho nos processos de terceirização?

Já na aprovação da Lei 8.949/94, houve reação negativa do então Ministro do Trabalho, Senhor Marcelo Pimentel, que sugeriu ao Presidente da República o veto da referida Lei, argumentando que:

«A Cooperativa que gerencia e distribui a prestação de serviços é intermediária da contratação de trabalho (o temido merchandage da doutrina mundial). Se for pretendida como lícita a sua existência, pre-

17 «Urge esclarecer de pronto que a importância do cooperativismo do trabalho não está exatamente em atender conjunturalmente uma demanda das empresas por relações de trabalho mais flexíveis, ou em baratear custos com mão de obra. Essas podem ser até conseqüências da introdução do cooperativismo de trabalho numa determinada economia, mas não são a sua razão de ser. A razão de ser da cooperativa de trabalho é a autogestão.

«Portanto, a existência de cooperativas de trabalho não pressupõe nem depende do sacrifício de seus direitos fundamentais pelo trabalhador individualmente considerado.

(...)

«Porém, para avançar nessa questão, já que está preconizando a identificação da natureza jurídica da relação de trabalho cooperado, melhor seria trilhar no campo do direito que permitisse a extração da essência da cooperativa de trabalho, sem que esta venha impregnada de elementos de Direito do Trabalho ou de Direito Civil, de forma que uns predominem sobre outros.»

18 «A análise do artigo $7^{\circ}$ da Constituição Federal deve se desenvolver à luz dos princípios garantidores da dignidade da pessoa humana consagrados pelos arts. 23 e 24 da Declaração Universal dos Direitos do Homem, as Convenções e Recomendações da Organização Internacional do Trabalho. É por essa razão que alguns direitos contidos no artigo $7^{\circ}$ da Constituição Federal estendem-se tanto para os trabalhadores empregados quanto para os trabalhadores em geral, dentre eles os sócios cooperados. Nesse sentido, a interpretação do mandamento constitucional não será restritiva.

"O vocábulo «trabalhadores» utilizado pela Constituição em seu artigo $7^{\circ}$ é genérico. Por assim dizer, trabalhadores são todos aqueles que exercem atividade laborativa, independentemente de estarem ou não empregados. Observa-se, nesse aspecto que a OCB não defende a simples aplicação dos direitos ali consagrados para todos os trabaIhadores de forma literal, visto que a redação do dispositivo constitucional está impregnado pelo paradigma celetista, o que, por conseqüência natural, excluiria os trabalhadores autônomos, por exemplo.» 
cisa assumir o papel de empregadora sempre que este papel seja assumido pelo tomador dos serviços.

«Se, porém, uma Cooperativa de Trabalho cobrar os serviços do tomador e contratar outro preço com o prestador dos serviços, é intermediária da prestação de serviços e deveria ser empregadora desses trabaIhadores sempre que não o fosse o próprio tomador dos serviços» ${ }^{19}$.

A aprovação da Lei 8.949/94, contrariando a vontade do Ministério do Trabalho, levou-o à conformação e à publicação, em 29 de setembro de 1995, da correta Portaria 925:

O Agente da Inspeção do Trabalho, quando da fiscalização na empresa tomadora de serviços de sociedade Cooperativa, no meio urbano ou rural, procederá ao levantamento físico objetivando detectar a existência dos requisitos da relação de emprego entre a empresa tomadora e os cooperados, nos termos do art. $3^{\circ}$ da CLT (vínculo empregatício: prestação de serviços que objetiva o atendimento de necessidade normal da tomadora e que se repete periódica e sistematicamente, sob a dependência econômica ou administrativa do tomador e mediante remuneração [salário]). Presentes os requisitos do art. $3^{\circ}$ da CLT, ensejará o Agente a lavratura de auto de infração.

Além disso, deverá o Agente verificar o enquadramento da Sociedade Cooperativa ao regime jurídico estabelecido na Lei 5.764/71, mediante a verificação das seguintes características:

- Número mínimo de 20 associados;

- Capital variável em quotas-partes dos associados, inacessíveis a terceiros, estranhos à sociedade;

- Limitação do número de quotas-partes para cada associado;

- Singularidade de voto;

- Quorum para as assembléias, baseado no número de associados, e não no capital;

- Retorno das sobras líquidas do exercício, proporcionalmente às operações realizadas pelo associado;

- Prestação de assistência ao associado;

— Fornecimento de serviços a terceiros atendendo a seus objetivos sociais.

Constatada a ausência das características da sociedade Cooperativa, deverá o Agente comunicar à chefia imediata, que apresentará denúncia à Procuradoria Regional do Trabalho.

Depois de muito debate, houve um alinhamento entre magistrados, procuradores e advogados em afirmar a existência de atividades labo-

19 Aviso/GM/MTb/n 502/94. 
rativas que, por sua natureza, demandam estado de subordinação. Comumente relacionavam as seguintes atividades com esta natureza subalterna, numa lista que se tornou virtualmente um índex inquisitorial para as cooperativas de trabalho:

- Limpeza;

- Conservação;

- Segurança, de vigilância e de portaria;

- Recepção;

- Copeiragem;

- Reprografia;

- Telefonia;

- Manutenção de prédios, de equipamentos, de veículos e de instalações;

- Secretariado e secretariado executivo;

- Auxiliar de escritório;

- Auxiliar administrativo;

- Office boy (contínuo);

- Digitação;

- Assessoria de imprensa e de relações públicas;

- Motorista, no caso de os veículos serem fornecidos pelo próprio órgão licitante;

- Ascensorista;

- Enfermagem;

- Agentes comunitários de saúde.

A chave hermenêutica aqui é o uso da expressão natureza. Em termos científicos, considerada a pretensão de cientificidade do Direito, natureza se manifesta entre a normalidade e a norma do acontecer, isto é, é aquilo que, na vigência do ente para todos (realidade), dele é expresso. É natural algo sujeito à determinação do seu acontecimento. Enfim, o que é natural não pode ser desnaturado sem destruir-se como algo dizível diante de si (ob-jectum). A natureza não pode ser desdita, senão re-significada na linguagem ${ }^{20}$.

20 «O homem, em suma, é inicialmente um dizer-se a si mesmo e, como sujeito, ele é essencialmente mediação entre o que é dizível - compreendendo o que designamos como polo Natureza (N) - e a expressão humana do que é dito - compreendendo o que designamos como polo Forma (F).

«(...) o símbolo fundamental com que o mundo se apresenta ao homem é o conceito de Natureza, e é em torno desse conceito que se desdobra a compreensão explicativa da relação de objetividade.»VAZ, Henrique C. de Lima. Antropologia Filosófica. Vol 2. São Paulo : Loyola, 1992. P.10; 24. 
Ao se pretender impedir que as cooperativas se inserissem em processos de terceirização desses serviços, se criou uma esdrúxula situação. Admitiu-se entidades constituídas por esses trabalhadores, capazes de constituírem instituições financeiras, cooperativas de crédito como expressamente admite e estimula a CLT e, pela Lei Complementar 130/2009, aptas a se tornarem controladoras de bancos cooperativos, como o Bansicredi e o Bancoob. Mas esses mesmos trabalhadores seriam, de acordo com um modo muito particular de se dizer natural dessa mesma CLT, incapazes de constituírem entidades, cooperativas de trabalho para simplesmente empreenderem a conservação das latrinas de outras entidades.

É óbvio que essa postulação, sempre escondida atrás da noção recorrentemente pejorativa, mas sempre preconceituosa de cooperativa de mão-de-obra, padecia de uma razão pouco rigorosa consigo mesma ${ }^{21}$. A falta de rigor foi particularmente evidente na situação admitida no seguinte precedente:

«FRAUDE. COLUSÃO. COOPERATIVA E COOPERADO. NECESSIDADE DE INTERVENÇÃO DO MINISTÉRIO PÚBLICO. Fortes indícios, nestes autos, de que pessoas espertas estão «montando» cooperativas «fantasmas», com associados mais «fantasmas» ainda, para entrarem com reclamações trabalhistas contra grandes empresas, certos de que, ante o enorme preconceito firmado contra elas, a chamada «tomadora» será de pronto condenada, sejam quais forem seus argumentos de defesa, obrigam a imediata intervenção do Ministério Público do Trabalho, a fim de que amplie investigações no sentido de apuração da existência de conluio entre cooperativa e cooperado, para fraudar terceiros inocentes.

"Sem esquecer que o dano maior não é o econômico, o material: é o moral, e se perfaz principalmente contra a administração da Justiça que, ao ser vítima de abuso e de engodo, pode perder sua credibilidade perante a sociedade» ${ }^{22}$.

21 Vale a pena lembrar aqui a preciosa lição de Hans-Georg Gadamer em Verdade e método ( 11. ${ }^{\text {a }}$ Ed. Petropolis: Vozes, 2011). Ele critica severamente as teorias que afirmam para si, por princípio, a isenção de preconceitos. A compreensão nunca se inicia do zero.

22 ACÓRDÃO N. ${ }^{\circ}$ 21896/2004 - PROCESSO TRT 15. ${ }^{a}$ REGIÃO N. ${ }^{\circ} 36374 / 00-R O-7$ (798-1998-082-15-00-1) RECURSO ORDINÁRIO - 5. ${ }^{a}$ TURMA - 10. ${ }^{a}$ CÂMARA - RECORRENTE: SUCOCÍTRICO CUTRALE LTDA.

$1^{\circ}$ RECORRIDO: EDCARLOS JOSÉ DE OLIVEIRA $2^{\circ}$ RECORRIDO: COOPERGLOBAL COOPERATIVA DE SERVIÇO E TRABALHO GLOBAL ORIGEM: $3 .{ }^{\circ}$ VARA DO TRABALHO DE SÃO JOSÉ DO RIO PRETO. 
Com base no princípio do contrato-realidade que rege as relações empregatícias, a relação de trabalho cooperativista não poderia mesmo assumir cumulativamente todas as características do emprego. Mas isso não impede, de forma alguma, que a cooperativa de trabalho possa ter como objeto lícito a prestação de quaisquer serviços terceirizáveis.

Não existem prestações de serviço ligados à atividade-meio do tomador, cujo labor, por sua própria natureza, demandaria execução em estado de subordinação em relação ao fornecedor dos serviços, senão num sentido pouco rigoroso de inexperiência. Quer dizer, não há na «natureza» de qualquer serviço determinação que permita a priori definir se ele será prestado sob o estado de subordinação celetista ou da cooperação. Ainda que, a posteriori, no contexto das cooperativas existentes nos anos 90, se podia duvidar da existência de alguma experiência de autogestão bem sucedida dessas atividades laborativas.

Em que pese essa inexperiência, qualquer serviço terceirizável pode ser prestado sob o regime de heterogestão ou autogestão - vai depender da sua forma. Heterogestão ou autogestão são modos distintos de processamento e organização do trabalho. Não pode haver nada que impeça a prestação de discriminados serviços laborativos ou profissionais pelo modo autogestionário, sem que se empreste a esses serviços alguma conotação diminutiva com relação a outros serviços em que se admita o modo autogestionário como possível. É como se na faxina e em outros serviços existisse algo vil que tornaria o trabalhador incapaz da autogestão ${ }^{23}$. Qualquer terceirização, para ser lícita ou ilícita, não depende de ser o prestador empresa ou coope-

23 A alegoria do lava-pés na narrativa bíblica é um eloquente alerta aos perigos éticos de alguma postulação neste sentido. Na alegoria, o próprio Deus se presta ao mais simples serviço de limpeza e asseio. Isso é enfatizado no diálogo havido entre Jesus e Pedro:

«Então Jesus se levantou da mesa, tirou o manto, pegou uma toalha e amarrou-a na cintura. Colocou água na bacia e começou a lavrar os pés dos discípulos, enxugando com a toalha que tinha na cintura. Chegou a vez de Simão Pedro. Este disse: Senhor, tu vais lavar os meus pés? Jesus respondeu: você agora não sabe o que estou fazendo. Ficará sabendo mais tarde. Pedro disse: Tu não vais lavar os meus pés nunca. Jesus respondeu: Se eu não o lavar, você não terá parte comigo. (....) Depois de lavar os pés dos discípulos, Jesus vestiu o manto, sentou-se de novo e perguntou: Vocês compreenderam o que acabei de fazer? Vocês dizem que eu sou o Mestre e o Senhor. E vocês têm razão; eu sou mesmo. Pois bem: eu, que sou o Mestre e o Senhor, lavei os seus pés; por isso vocês devem lavar os pés uns dos outros. Eu lhes dei um exemplo: vocês devem fazer a mesma coisa que eu fiz. Eu garanto a vocês: o servo não é maior do que o senhor; nem o mensageiro é maior do que aquele que o enviou. Se vocês compreenderem isso, serão felizes se o puserem em prática.» (Jo 13:4-8;12-17) Nesse passo, não pode existir subalternidade intrínseca na natureza de qualquer trabalho, sem que se empreste a algum trabalho alguma medida de indignidade. 
rativa, mas depende da autonomia dos trabalhadores em relação ao tomador dos serviços.

A cooperativa é o tipo jurídico típico da autogestão e a relação de trabalho estabelecida interna corporis nos moldes previstos pela Lei 5.764/71 (art. 90) não se configura empregatícia; se preservada a autonomia coletiva dos trabalhadores cooperados em relação ao tomador, a terceirização será lícita, ainda que não se verifique a existência de relação de emprego na prestação. Impedir a participação de cooperativas no mercado de serviços terceirizáveis tem um efeito perverso: frustra desde sempre a concorrência possível pela negativa à possibilidade dos trabalhadores se organizarem autogestionariamente e favorece a permanência só de sociedades empresárias nesses mercados. De um modo oblíquo, se postula que há trabalhos em que a sua exploração por patrões é natural, dada a subalternidade intrínseca dessas atividades.

Essa questão foi criteriosamente observada na Recomendação 193 sobre a promoção das Cooperativas votada na plenária da $90 .{ }^{a}$ Conferência da OIT em 20.06.2002. Em seu item 1 (âmbito de aplicação, definição e objetivos) «se reconhece que as cooperativas operam em todos os setores da economia. Esta Recomendação se aplica a todos os tipos e formas de cooperativas.» Outrossim, o seu item 7.2 (marco político e papel dos governos) declara que:

"as cooperativas devem se beneficiar de condições conformes com a legislação e as práticas nacionais que não sejam menos favoráveis que as que se concedam a outras formas de empresa e de organização social.»

Ainda que fosse o caso de preservar os tomadores da responsabilidade subsidiária em casos frequentes de abuso de forma cooperativista, bastava exigir que a cooperativa concorrente assinasse a carteira de trabalho dos mesmos - o que é expressamente admitido no art. 31 da Lei 5.764/71, até que uma experiência autogestionária entre eles pudesse ser amadurecida. Seria uma solução atenta à Recomendação da OIT na sua integralidade.

Em que pesem esses argumentos, a ideia do Index dos serviços terceirizáveis vedados às cooperativas de trabalho prosperou entre profissionais ligados ao direito do trabalho. Foi recorrente o uso de argumento no sentido de que a autonomia exigida do trabalhador pressupõe uma horizontalidade entre cooperados. Ou seja, qualquer forma de coordenação do trabalho realizado por cooperados demandava estado de subordinação trabalhista deles. 
Curiosamente, essa horizontalidade não foi exigida com o mesmo rigor das cooperativas organizadas por trabalhadores de fábricas, credores de massas falidas, que as assumiam em solução de continuidade das operações e conservação dos postos de trabalho. Neste caso, falava-se então na detenção dos meios de produção como excludente da subordinação, mesmo diante da evidente verticalização na gestão do trabalho.

Pelo visto, dava-se o preconceito discriminativo face à participação de cooperativas de trabalho no mercado de serviços terceirizáveis pela conjugação de dois fatores: o afrouxamento da autogestão na prática das cooperativas de trabalho e a influência do utilitarismo na atuação de procuradores e magistrados especializados.

O afrouxamento da autogestão na prática do cooperativismo do trabalho nos anos 90 teve como origem a já abordada influência no ramo de um discurso estranho à doutrina cooperativista,. Este discurso se originou nos gestores de recursos Humanos das empresas, para os quais a razão das cooperativas é a flexibilização das relações de trabalho e o barateamento da mão de obra. A cooperativa de trabalho, nos anos 90, foi querida pelos tomadores de serviços, mas não pelos sindicatos de trabalhadores. Para o trabalhador, a relação de trabalho cooperativa acabou sendo sempre colocada como alternativa, não ao emprego, mas ao desemprego. Neste passo, na prática, a relação de trabalho cooperativa passou a ser percebida pelos trabalhadores como uma oferta de qualidade inferior ao emprego. Imposto, não desejado. O emprego permaneceu como o objeto de desejo e em contraponto a uma indesejada realidade da relação societária cooperativa.

O paradigma dessa cooperativa de autogestão frouxa foi as cooperativas que se ofereciam no mercado de serviços terceirizáveis com área de ação nacional e sem objeto definido - comumente chamadas de multiprofissionais. Nos anos 90, essas cooperativas se pretendiam um modelo de sucesso para o ramo de trabalho do cooperativismo brasileiro. Os atos democráticos de gestão eram encarados como ônus que a cooperativa se desincumbia como uma formalidade vazia de significado transcendente, e não como atos de efetiva participação do quadro social na gestão do trabalho e, como tal, essenciais à legitimação do ato cooperativo de trabalho.

Muitos gestores de cooperativas de trabalho não se deram conta do perigo representado pelo esvaziamento da affectio societatis entre os trabalhadores na base da cadeia de comando operacional na prestação de serviços com os tomadores. Era perceptível que, sendo o emprego o objeto de desejo desses trabalhadores, os gestores eram os únicos com ânimo de permanência na cooperativa. As cooperativas de trabalho assim se deslegitimaram perante os operadores do direito do trabalho. 
A massificação do quadro social das cooperativas de trabalho apresenta ao cooperativismo questões que a teoria do ato cooperativo, sem os avanços propostos sobretudo a partir dos Critérios para Identidade das Cooperativas de Trabalho aprovados pela OCB, não dava conta. ${ }^{24}$

Nas soluções exigidas pelos problemas de justiça surgidos nas sociedades de massa, a igualdade individual, jurídica e formal, não prepon-

24 Está em gestação uma nova teoria para o ato cooperativo, superando a dicotomia entre as teorias pura e teoria mista. A teoria mista não consegue distinguir bem o ato cooperativo do ato de mercado. Entretanto, na teoria pura há clareza que o ato praticado entre o cooperado e a cooperativa é diferente do ato de mercado. Essa é uma questão fundamental de onde parte a distinção entre não só o trabalhador sócio da cooperativa de trabalho e o empregado, mas também entre o consumidor sócio da cooperativa de consumo ou de eletrificação rural e o consumidor de que trata o Código de Defesa do Consumidor; entre o médico ou odontólogo sócios de cooperativa operadora e o médico ou odontólogo credenciado por empresa operadora e seus reflexos no direito concorrencial.

Por outro lado, a teoria pura não mais consegue ser bem compreendida, pois ele é basicamente uma manifestação tardia das teorias voluntaristas no Direito Civil. E as teorias voluntaristas estão cada vez menos paradigmáticas. Por isso, comumente o operador de direito e os leigos percebem um encadeamento de atos originados no interior da cooperativa e projetado para fora da cooperativa, no mercado. É um olhar influenciado pelo estruturalismo, porque está focado na estrutura dessa cadeia. Para a problemática que se percebe com esse olhar, a teoria pura, por si mesma, não dá conta de fornecer elementos conceituais suficientes, pois ela não está preocupada em exaurir reflexão sobre a cadeia distinta, mas apenas em identificar a sua gênese distintiva, que é a ausência de interesse oposto nos atos praticados entre a cooperativa e seu cooperado.

Por esse encadeamento, há uma tendência no operador de direito e até mesmo o leigo a unificar, chamando tudo que está encadeado, por metonímia, de ato cooperativo, para determinar um tratamento tributário, ou societário, diferenciado. Ao realizar esse processo lingüístico, a premissa distintiva fundamental entre o que acontece entre a cooperativa e seu sócio, de natureza diversa do que acontece entre a cooperativa e o mercado, resta em eclipse, mas não alterado.

Por outro lado, na medida em que as relações cooperativas se massificam não somente na sociedade, mas no interior do quadro societário das cooperativas, forçoso é admitir que as soluções baseadas unicamente no voluntarismo (igualdade formal entre os sócios redunda numa irrestrita liberdade formal entre o sócio e a cooperativa) sobre o qual se assenta atualmente a doutrina sobre o ato cooperativo não é suficiente. Não se pode levar ao judiciário, imaginando que as cooperativas sairão vitoriosas da refrega, diante de uma situação conflituosa envolvendo a dignidade da condição do trabalhador, a alternativa entre aplicar a CLT, ou nenhuma lei ou regra específica para essa relação de trabalho, sujeita essa dignidade a uma convenção puramente privada, ainda que assemblear. Como não se pode, num conflito envolvendo o sócio consumidor e a cooperativa de consumo, a aplicação do CDC ou nenhuma regra específica para essa relação de consumo.

Porém, essas questões pragmáticas não podem ser resolvidas com casuísmos, sob pena de graves danos ao próprio cooperativismo, em longo prazo, por perda de sua consistência e coerência sistêmica. Uma nova teoria parte do ponto central da teoria pura, ou seja, o caráter singular da relação havida entre o sócio e sua cooperativa, mas sistematiza a fenomenologia para uma compreensão coerente e consistente da cadeia operacional ou econômica na qual esse ponto central tem impacto condicionante. 
dera ante o desequilíbrio de forças econômicas das partes relacionadas ou, mesmo os efeitos efetivos ou potencialmente nocivos em relação a terceiros. Nesses casos, é justo que o Estado imponha um sistema de contrapesos jurídicos à atuação do particular. Porém, a solução não é fácil como aparenta, porque a igualdade individual, jurídica e formal, é necessária como garantia da liberdade.

Aqui surge a questão utilitarista. Ou melhor, são duas as questões:

1. A liberdade individual deve se sujeitar a um cálculo de interesses sociais?

2. É necessária a construção de uma única concepção juridicamente válida de bem e justo para a solução de um problema social?

Um duplo sim às questões postas foi o pressuposto utilitarista para o alinhamento de operadores do Direito do Trabalho no sentido de se restringir o acesso de cooperativas de trabalho ao mercado de serviços terceirizáveis como solução ao quadro de abusos de forma e desvios de finalidade que atingiram o cooperativismo.

Sob uma perspectiva utilitarista, foi justo que o direito à autogestão tenha sido negado, a fim de se proteger um contigente significativo de trabalhadores vítimas efetivas e potenciais de abusos de forma cooperativa e desvios de finalidade cooperativista. Até porque o vínculo de emprego era o único meio pelo qual um trabalhador tinha eficazmente assegurada a dignidade do trabalho, quando prestava serviços não eventuais e mão-de-obra intensivos a um único tomador por vez.

No entanto, os cooperativistas se socorrem na crítica de JOHN RAWLS ao utilitarismo ${ }^{25}$. As pessoas possuem diferentes valores e formu-

25 «A proposição central do utilitarismo, pelo menos na sua forma clássica, é o princípio da maior felicidade. De acordo com este princípio, o melhor resultado é aquele que maximiza a felicidade agregada dos membros de uma sociedade tomada como um todo. Todavia, em algumas circunstâncias plausíveis, pode acontecer que a maneira de maximizar a felicidade agregada signifique impor um sofrimento considerável a um ou a alguns membros de uma sociedade.

«(...) Na opinião de Rawls, ainda que os utilitaristas aceitem que diferentes coisas contribuam para o bem, pressupõem que isso acontece porque contribuem para o bemestar psicológico, que é, só por si, o único bem. Rawls pensa que este pressuposto está errado. Na sua perspectiva, há uma concepção pluralista de diferentes e até incomensuráveis concepções de bem e assim continuaria a ser mesmo que todas as pessoas fossem muitíssimo informadas e racionais. As pessoas possuem diferentes valores e formulam diferentes projetos. Alguns destes valores e projetos ultrapassam a sua própria vida e experiência individual. Isso é, alguns indivíduos — muitos indivíduos, de fato- valorizam outras coisas para além de estados mentais ou estados de bem-estar psicológico.» JOHNSTON, David. The Idea of a Liberal Theory: A Critique and Reconstruction. New Jersey: Princeton Universtity Press, 1996, pp. 101-3 (Trad. Vítor João Oliveira). 
lam diferentes projetos para a realização do bem comum. Às vezes, esses projetos versam sobre o mesmo objeto e realidade e, mesmo assim, são heteronômicos. Isso é particularmente relevante para o cooperativista que está longe de ignorar o que é universalmente exigido para a garantia da dignidade do trabalho. E o que é justo deve levar em consideração essa pluralidade de concepções da legitimidade. Na medida em que essa diversidade cooperativista é admitida no mundo do trabaIho, então o sacrifício do direito de escolha à autogestão não é justa.

O cooperativismo agora tem uma positivação que lhe permite reivindicar um novo realinhamento dos operadores do Direito Trabalhista sobre as amplas possibilidades da autogestão, sem prejuízos à dignidade e à decência do trabalho. Esse realinhamento passa por uma tríplice garantia:

- Garantia de direitos sociais mínimos para os sócios das cooperativas de trabalho, quando da prestação de serviços não eventuais (como adicionais por jornadas anormais de trabalho, ou noturno, insalubre, perigoso, ou penoso, bem como descansos semanais e anuais remunerados);

- Garantia à autogestão, obrigando a cooperativa, em assembléia geral, estabelecer as condições gerais para o exercício desses direitos pelos cooperados, bem como esses trabalhadores, quando organizados em equipes, elegerem seus líderes e estabelecerem as condições específicas de trabalho não eventual contratado.

- Garantia à participação das cooperativas de trabalho em todos os mercados, inclusive os de serviços terceirizáveis, com os mesmos limites fixados às demais sociedades (atividade-meio).

A sociedade brasileira não pode se contentar com um sentido utilitarista de se ministrar justiça. Justiça não é matemática. Por isso, a segurança e a defesa de trabalhadores vítimas efetivas ou potenciais de abusos de forma cooperativa ou atuantes em desvio de suas finalidades, ainda que numerosos, não pode justificar o sacrifício de uma liberdade individual. A autogestão é um direito de todo trabalhador e qualquer trabalhador é capaz dela.

Alguns operadores do Direito do Trabalho podem se perguntar se existe uma cooperativa verdadeira de faxineiros, ou de colhedores de laranjas. A doutrina cooperativista informa, de modo consistente e coerente, as condições próprias dessa existência.

O combate e a prevenção à precarização do trabalho precisavam resolver problemas comuns nas experiências existentes a sua época, mas também precisam estar agora submetidos a um olhar atento ao modo como isso é feito, na medida em que projeta seus efeitos de aniquila- 
ção para o futuro. É este um grande ensinamento que Sófocles deixou em Antígona. Sua crítica leva em consideração essa projeção.

O Ministro Gilmar Ferreira Mendes, em sua obra Direitos Fundamentais e Controle de Constitucionalidade, enfatiza que, de acordo com as doutrinas constitucionais contemporâneas, em se tratando de imposição de restrições a determinados direitos, deve-se indagar não apenas sobre a admissibilidade constitucional da restrição eventualmente fixada (reserva legal), mas também sobre a compatibilidade das restrições estabelecidas com o princípio da proporcionalidade.

Esta nova orientação, continua ele, «permitiu converter o princípio da reserva legal (Gesetzvorbehalt) no princípio da reserva legal proporcional (Vorbehalt des Verhältnismässigen Gesetzes), pressupõe não só a legitimidade dos meios utilizados e dos fins perseguidos pelo legislador, mas também a adequação desses meios para consecução dos objetivos pretendidos (Geeignetheit) e a necessidade de sua utilização (notwendigkeit oder erforderlichkeit)».

Mesmo que no passado, ou mesmo agora, nem uma única cooperativa de faxineiros, ou de mecânicos, ou de vigilantes, ou de porteiros, ou de recepcionistas, ou de copeiros, ou de operadores de equipamentos reprográficos ou de telefonia, ou de secretárias, ou de assessores de imprensa, ou de relações públicas, ou de digitadores, ou de ascensoristas, ou de motoristas, ou de enfermeiras estivesse funcionando adequadamente, esse fato não pode para sempre negar a possibilidade de licitude, porque ela é cogitada a partir de razoáveis condições.

O direito nunca é inteiramente justo, sobretudo quando decreta a morte de uma utopia.

A Lei 12.690/2012 positivou definições teleológicas. Em Verdade e Conjetura, Miguel Reale (REALE, 1983, p.98) notou: "O valor é um ente autônomo, por ser-lhe inerente um sentido vetorial de dever-ser, em razão do qual se põem os fins, os quais podem ser vistos como 'vestes racionais do valor».

A intenção foi evidente: ponderar o princípio da concreção a ser aplicada pela magistratura trabalhista. O princípio da concreção se refere à ação construtiva da jurisprudência e o trabalho criador da hermenêutica. Os art. $2 .^{\circ}$ e $3 .^{\circ}$ programam a narrativa que condiciona essa ação construtiva por sentidos específicos ${ }^{26}$.

26 Art. 2.o Considera-se Cooperativa de Trabalho a sociedade constituída por trabalhadores para o exercício de suas atividades laborativas ou profissionais com proveito comum, autonomia e autogestão para obterem melhor qualificação, renda, situação socioeconômica e condições gerais de trabalho. 
Pode-se indagar pela pertinência de um texto de lei infraconstitucional que não prescreve. Ao contrário, é dirigido aos seus próprios fundamentos imaginários; diz de seus próprios mitos fundadores. Isto é, inscreve. A Lei 12.690/2012 assume, portanto, que sua preocupação é menos delimitar sua eficácia face à CLT, mas instituir a plena eficácia para o ato cooperativo de trabalho. Os seus arts. $2 .^{\circ}$ e $3 .^{\circ}$ imprimem ao ato cooperativo de trabalho um fundo performativo para os seus atores, mais do que uma ordenação a esse ato. Há certo encantamento, um viés ficcional que não trata de domínio sobre o fazer, nem de suas finalidades, mas que se volta às instituições com as quais certa narrativa socialmente consistente também vige juridicamente.

A inclusão do art. $2^{\circ}$ no texto legal responde aos mais recorrentes equívocos conceituais referentes à instituição cooperativa e em torno da Lei 8.949/94, tanto por parte de profissionais na administração de recursos humanos e cooperativistas, num temerário vale-tudo, como de magistrados e procuradores do trabalho, num reativo nada vale. Enfim, a Lei, no art. $2^{\circ}$, desafia a um reescrever sobre as cooperativas de trabalho. O Ministro Ives Gandra Martins Filho, em pronunciamento diante da notícia de publicação da Lei 12.960/2012, soube dar voz à esfinge:

«Os únicos marcos normativos nacionais, até o momento, que balizavam as cooperativas de trabalho, eram a genérica Lei n. ${ }^{\circ}$ 5.764/71, sobre o cooperativismo e suas modalidades, e o art. 442, parágrafo único, da Consolidação das Leis do Trabalho (CLT), que afastava o

$\S 1 .^{\circ}$ A autonomia de que trata o caput deste artigo deve ser exercida de forma coletiva e coordenada, mediante a fixação, em Assembleia Geral, das regras de funcionamento da cooperativa e da forma de execução dos trabalhos, nos termos desta Lei.

$\S 2 .^{\circ}$ Considera-se autogestão o processo democrático no qual a Assembleia Geral define as diretrizes para o funcionamento e as operações da cooperativa, e os sócios decidem sobre a forma de execução dos trabalhos, nos termos da lei.

Art. 3. ${ }^{\circ}$ A Cooperativa de Trabalho rege-se pelos seguintes princípios e valores:

I - adesão voluntária e livre;

II - gestão democrática;

III - participação econômica dos membros;

IV - autonomia e independência;

$V$ - educação, formação e informação;

VI - intercooperação;

VII - interesse pela comunidade;

VIII - preservação dos direitos sociais, do valor social do trabalho e da livre iniciativa;

IX - não precarização do trabalho;

$X$ - respeito às decisões de asssembleia, observado o disposto nesta Lei;

XI - participação na gestão em todos os níveis de decisão de acordo com o previsto em lei e no Estatuto Social. 
vínculo empregatício entre os trabalhadores cooperados e as cooperativas ou tomadoras de seus serviços.

«Tais marcos eram notoriamente insuficientes para regular o fenômeno, tanto que houve claro desvirtuamento da modalidade associativa, gerando as falsas cooperativas de trabalho, cujo intuito era exclusivamente burlar a legislação trabalhista, reduzindo custos de contratação de mão de obra pelas empresas.

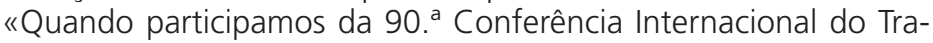
balho, em Genebra, no ano de 2002, denunciamos essa prática desvirtuadora do instituto, conseguindo que fosse inserido na Recomendação n. ${ }^{\circ} 193$ da Organização Internacional do Trabalho (OIT) dispositivo específico recomendando o combate às falsas cooperativas, que não garantiam aos trabalhadores todos os direitos constitucionalmente assegurados (item 8.1.b).

«Se, por um lado, nessa conferência, se alertou para o problema que ocorria em países em desenvolvimento com as falsas cooperativas de trabalho, essa modalidade organizativa foi amplamente prestigiada com a referida recomendação, como forma de estímulo à empregabilidade e à autogestão empreendedora dos trabalhadores. Tanto que, num de seus dispositivos, a Recomendação estabelece que não se pode dar às cooperativas de trabalho condições menos favoráveis do que às empresas que se dediquem ao mesmo ramo produtivo ou de serviços (item 7.2).

«Por isso chamou a atenção a exigência, pelo Ministério Público do Trabalho, de que a União firmasse termo de ajuste de conduta, alijando das licitações públicas as cooperativas de trabalho, numa atitude preconceituosa e generalizadora quanto às irregularidades de algumas cooperativas, condenando o próprio instituto, ao arrepio da Constituição, da lei e das normas internacionais de estímulo ao cooperativismo laboral» ${ }^{27}$.

\section{Bibliografia}

BENTO XVI. Caritas in Veritate.: http://www.vatican.va/holy_father/benedict_ xvi/encyclicals/documents/hf_ben-xvi_enc_20090629_caritas-in-veritate_ po.html.

DERRIDA, Jacques. Força de lei. Trad. Leyla Perrone-Moyses. São Paulo: Martins Fontes, 2007.

DESCARTES, René. Discurso do Método in: Os Pensadores. vol. XV. São Paulo: Abril Cultural, 1973.

27 http://clippingmp.planejamento.gov.br/cadastros/noticias/2012/7/22/o-resgatedo-cooperativismo-de-trabalho/. 
DWORKIN, Ronald. O império do Direito. São Paulo: Martins fontes, 2007. p. 287

GUIMARÃES, Aquiles Côrtes. Para Uma Teoria Fenomenológica do Direito -III. Cadernos da escola de Magistratura Regional Federal da 2 Região Fenomenologia e Direito. Vol. 4, nº 1 (abr/set 2011). Rio de Janeiro: TRF 2. ${ }^{a}$ Região, 2008.

- Para uma teoria fenomenológica do Direito - IV. Cadernos da escola de Magistratura Regional Federal da 2 Região fenomenologia e direito. Vol.

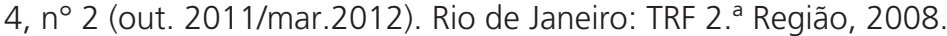

HARTMANN, Nicolai. Ontologia. Vol 1. 2. ${ }^{a}$ ed. Trad. José Gaos. Cid. Mexico: Cultura Econômica, 1965.

HEIDEGGER, Martin. Aportes A La Filosofia. Trad. Dina V. Picotti C. Buenos Aires: Biblos, 1993

-, Sobre o Humanismo. 2. ${ }^{\text {a }}$ ed. Rio de Janeiro: Editora Tempo Brasileiro, 1995.

INTERNATIONAL LABOUR OFFICE. Labour Law and Cooperatives: Experiences form Argentina, Costa Rica, France, Israel, Italy, Peru, Spain and Turkey. Geneva: ILO : 1995.

KRUEGER, Guilherme; DE CONTO, Mario. Ato cooperativo: Considerações a partir dos pressupostos da hermenêutica filosófica. KRUEGER, Guilherme (Coord.) . Cooperativas na ordem econômica constitucional. Belo Horizonte: Mandamentos, 2008.

OST, François. Contar a Lei: As Fontes Do Imaginário Juridico. Trad. Paulo Neves. São Leopoldo: Editora Unisinos, 2004.

REALE, Miguel. Verdade e Conjetura. Rio de Janeiro: Nova Fronteira, 1983.

RICOEUR. Paul. Tempo e narrativa. Tomo III. Trad. Claudia Berliner. São Paulo: Martins Fontes, 2010.

SCHELER, Max. Ética. Tomo I. Trad. Hilário Rodriguez Sanz. Buenos Aires: Revista de Occidente Argentina, 1948. 